\title{
フィルム包装における光線の影響に関する研究一II. 桜でんぶの光線による変色について
}

渡辺 渉・小林 晃・久末寿昭・川北 紘

(1966 年 5 月 14 日受理)

\section{STUDIES ON INFLUENCE OF RAYS UPON FILM-PACKING-II. DISCOLORATION OF THE FILM-PACKED "SAKURA- DEMBU” IRRADIATED WITH ULTRAVIOLET RAY}

\author{
Wataru Watanabe, Akira Kobayashi, Toshiaki Hisasue, \\ and Hiroshi KawaKiTA*
}

The shelf-life of "sakura-dembu", seasoned cod meals, is not long because of discoloration or browning.

The phenomena were considered to be caused partly by rays.

The authors prepared cod meals, each of which was colored with one ingredient of coloring substance and adjusted each of the water contents ranging from 5 to $30 \%$.

Each of all the materials was divided into three groups and packed with three film materials having different permeability against rays and oxygen. All samples were irradiated with ultraviolet ray and then the differences of color were measured.

The results are as follows:

(1) The least discoloration was measured with the "sakura-dembu" samples packed with the film having the lowest permeability against ultraviolet ray.

(2) The strongest discoloration was found with the samples colored with Red 103 or Red 104. The discolortion of "sakura-dembu" products may be caused chiefly by that of these coloring substances.

(3) The higher the water content of the sample was, the stronger the discoloration by irradiation with ultraviolet ray was. However, the curves of the increase of discoloration versus water content were not exponential; but distinct increases were noticed with the samples with water contents between 10 and $20 \%$.

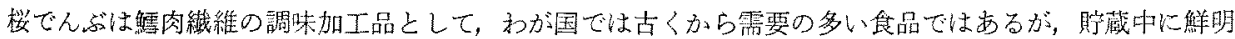
な淡縕色が裉色，また褐变するために，品質保持期間は一力月内外が普通である。この現象の一つの瑟因と しては，水との共存下におけ光光線の影韫が考えられる。

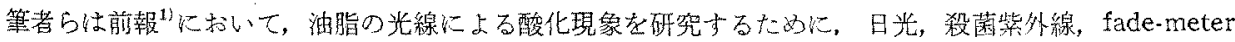

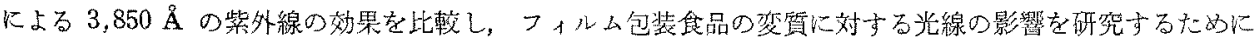
は，fade-meter による照射が最も效果的であることを指摘した。この結果に基き，本実鈳でも fade-meter

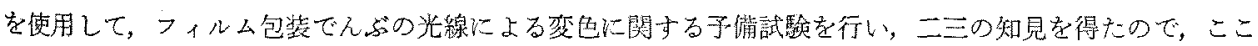
に報告する。

* 株式会社二幸・研究所 (Research Laboratory, Niko Co., Ltd.) 


\section{実 験 方 法}

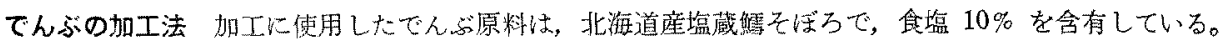

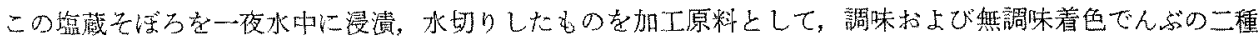
類に加工した。

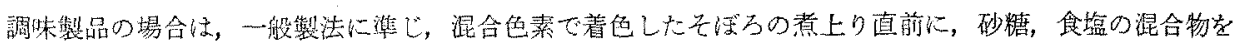
峺燥粉末のまま添加し，罟拌混合したが，この方法では調味料は一部しか溶解，吸着されない状態（混合型

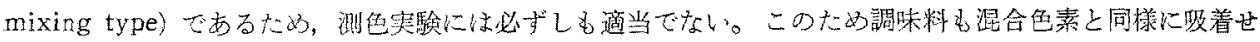

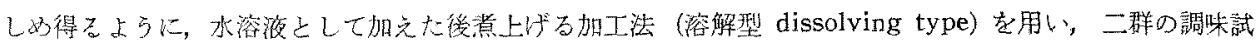

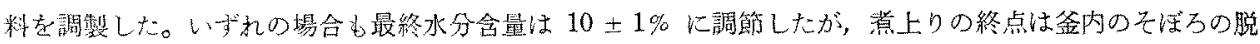

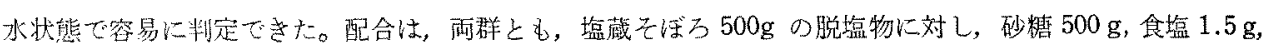
混合色素 $0.16 \mathrm{~g}$ である。混合色素の配合は赤色 103 号 $56 \mathrm{mg}$ ，赤色 104 号 $4.8 \mathrm{mg}$ ，赤色 106 号 $96 \mathrm{mg}$, 黄色 4 号 $3.2 \mathrm{mg}$ であつた。

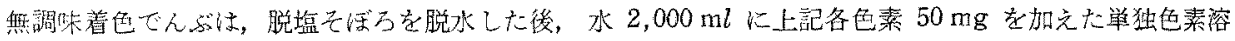

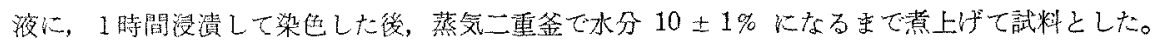

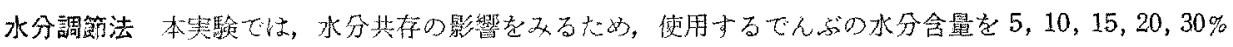

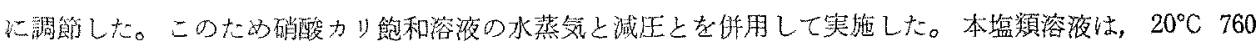
$\mathrm{mmHg}$ で，相対湿度 $95 \%$ が得られることが知られて㧍り ${ }^{231}$ ，これを減王空間飞收容することに上り，定

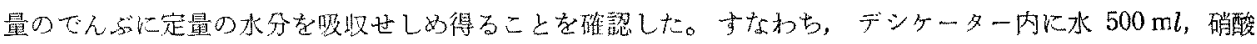

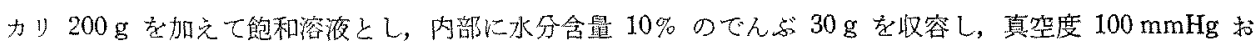

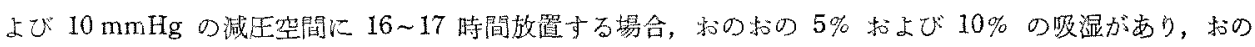
手の $15 \%$ ，20\% 水分含量之なる。水分 $30 \%$ の試料はこの操作の反徣て得られ，含有誤差は $30 \%$ では $\pm 2 \%, 20,15 \%$ で $\pm 1 \%$ であつた。水分 $5 \%$ 試料は, 同最のでんぶを塩化カルシウム入りの畭燥用デシ ケーター中に 16 17 時間放置することにより得られた。との誤差は士1\%であつた。

包装材料包装材料としては，前報に使用した材料の中の三種類を使用した。すなわち，酸素および紫 外線の透過性大なる高生法ポリエチレン，酸素透過性小で紫外線透過性大なる普通種ポリ七ロ，酸素透過性 大て紫外線遮渦性小の紫外線阻止郕含有ポリプロピレン（以下 UVPP）である。

実 験 法 調味製品は二群とも $10 \%$ 水分試料を吸湿法によつて $20 \%$ 水分含量としてから，また，無 調味着色でんぶは $10 \%$ 水分試料から， $5,10 ， 15 ， 20 ， 30 \%$ の水分含量に補正した後，各 $1 \mathrm{~g}$ を内佳 $40 \times 50 \mathrm{~mm}$ の㱔内に収容し，手で平になる程度に排気して加熱接着し，実龭試料上した。。

紫外線照射前報同樣，東洋理化工業製 fade-meter (主波長 3,850 ) を使用し，照射距離 $250 \mathrm{~mm}$ ，温 度 $40^{\circ} \mathrm{C}$ の条件下で 1 時間の照射後, 日本霓色工業製 ND 5 型測色色差計て $L, a, b$, 老湘定し, 照射前の 測定結果上の比較により色差 $\Delta E=\sqrt{ } \bar{\Delta} \overline{L^{2}+\Delta \bar{a}^{2}+\Delta \bar{b}^{2}}$ を求めた。各陚料は照射時の高温などにより，処理 中に乾燥現象至認めたが，30\% 水分試料で $2 \% ， 20 \sim 10 \%$ 水分武料で $1 \% ， 5 \%$ 水分試料で $0.2 \%$ の最 高減量を示した。娰照試料は紫外線照射老除いては同一の取报いで，測色も同時に実施した。

\section{結果および考察}

調味でんぶの変色一般的な製法による混合型製品は，白色調味料結晶中に着色でんぶが混在するため，

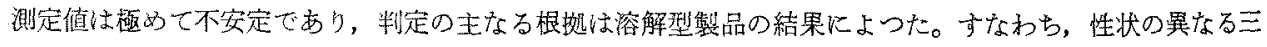
種頪の包装村料で含気包装し, 紫外線照射を行つた両型でんぶについての測定の結果, 得られた $L, a, b$, $\triangle E$ の値を Table 1 に示す。

表にみるごとく，也差 $A E$ につては，UVPP の場合が最低で紫外線阻止効果を示している。また，一 般に，紫外線の照射に上り $a$ 値の减少，すなわち赤の褪色が恐められる。L 值の結果から明度は多少上昇 
Table 1. Discoloration of two types of film-packed "Sakura-dembu" by irradiation with ultraviolet ray.

\begin{tabular}{|c|c|c|c|c|c|c|}
\hline Treatment & \multicolumn{2}{|c|}{ Film specimen } & $L$ & $a$ & $b$ & $\Delta E$ \\
\hline \multirow{3}{*}{$\begin{array}{c}\text { Mixing } \\
\text { type }\end{array}$} & $\begin{array}{l}\text { Low density } \\
\text { Polyethylene }\end{array}$ & $\begin{array}{l}\text { Control } \\
\text { Irradiation }\end{array}$ & $\begin{array}{l}47.3 \\
44.7\end{array}$ & $\begin{array}{l}34.2 \\
29.5\end{array}$ & $\begin{array}{l}9.7 \\
9.2\end{array}$ & 5.5 \\
\hline & Polycello & $\begin{array}{l}\text { Control } \\
\text { Irradiation }\end{array}$ & $\begin{array}{l}45.5 \\
44.5\end{array}$ & $\begin{array}{l}35.4 \\
28.9\end{array}$ & $\begin{array}{l}10.2 \\
10.1\end{array}$ & 6.6 \\
\hline & UV-polypropylene & $\begin{array}{l}\text { Control } \\
\text { Irradiation }\end{array}$ & $\begin{array}{l}47.1 \\
44.2\end{array}$ & $\begin{array}{l}35.7 \\
31.9\end{array}$ & $\begin{array}{l}10.2 \\
10.1\end{array}$ & 4.8 \\
\hline \multirow{3}{*}{$\begin{array}{l}\text { Dissolving } \\
\text { type }\end{array}$} & $\begin{array}{l}\text { Low density } \\
\text { Polyethylene }\end{array}$ & $\begin{array}{l}\text { Control } \\
\text { Irradiation }\end{array}$ & $\begin{array}{l}50.3 \\
51.3\end{array}$ & $\begin{array}{l}34.1 \\
27.0\end{array}$ & $\begin{array}{r}9.4 \\
10 \cdot 9\end{array}$ & 7.4 \\
\hline & Polycello & $\begin{array}{l}\text { Control } \\
\text { Irradiation }\end{array}$ & $\begin{array}{l}49.4 \\
51.4\end{array}$ & $\begin{array}{l}35.2 \\
28.8\end{array}$ & $\begin{array}{r}9.7 \\
10.2\end{array}$ & 6.9 \\
\hline & UV-Polypropylene & $\begin{array}{l}\text { Control } \\
\text { Irradiation }\end{array}$ & $\begin{array}{l}50.3 \\
50.5\end{array}$ & $\begin{array}{l}35.4 \\
29.1\end{array}$ & $\begin{array}{l}10.1 \\
11.1\end{array}$ & 6.4 \\
\hline
\end{tabular}

し，b䛧からは黄色のわずかな增加が認められる。

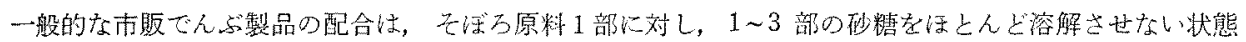

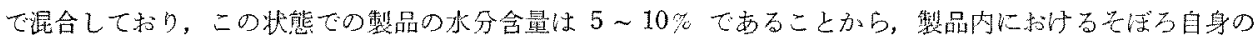

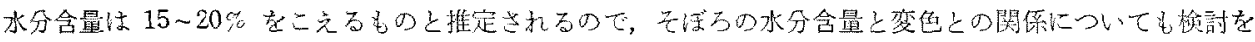
要求ると思尗れる。

無調味着色てんふの变色 着色料単色の変化をみるために，前記調味試料実験に用いた混合色素の他に，

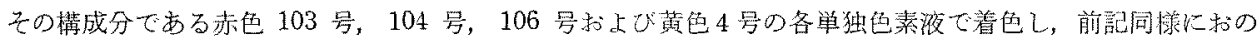

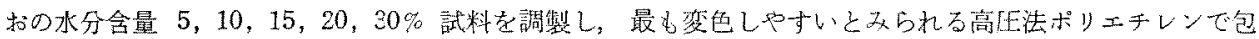

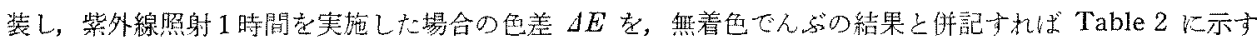
通りである。

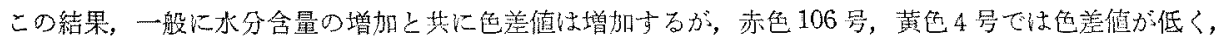

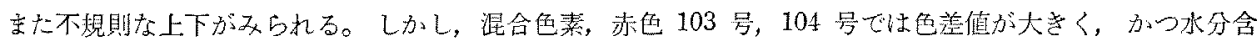
量の增加による色差㑑のいちじるしい增大がみられる。したがつて，混合色素による着色でんふの变色は， 赤色 103 号，104号の紫外線による変色に起因寸るものと考之られる。

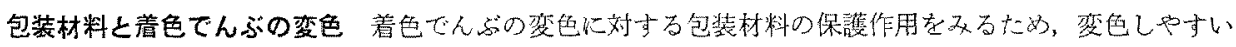
赤色 103 号, 104 号で着色したでんぶを, 高正法ボリェチレン，普通種ボリセロ，UVPPの3種類のフィ ルムで包装穾験した。すなわち，5３0\% に水分調整を行つた包装着色でんぶを，同一条件下で紫外線照射

Table 2. Color differences of colored cod meals which contained various contents of water and irradiated with ultraviolet ray.

\begin{tabular}{l|l|l|l|l|l}
\hline Water content \% & 5 & 10 & 15 & 20 & 30 \\
\hline $\begin{array}{l}\text { Coloring substance } \\
\text { mixture }\end{array}$ & 1.1 & 1.4 & 2.0 & 3.6 & 5.0 \\
Non color & 1.0 & 1.9 & 1.3 & 2.1 & 2.0 \\
Red 103 & 2.2 & 2.3 & 4.9 & 7.3 & 9.8 \\
Red 104 & 2.4 & 4.4 & 6.4 & 9.6 & 11.1 \\
Red 106 & 1.0 & 1.2 & 2.7 & 2.6 & 2.8 \\
Yellow 4 & 0.6 & 1.5 & 1.2 & 1.5 & 2.5 \\
\hline
\end{tabular}




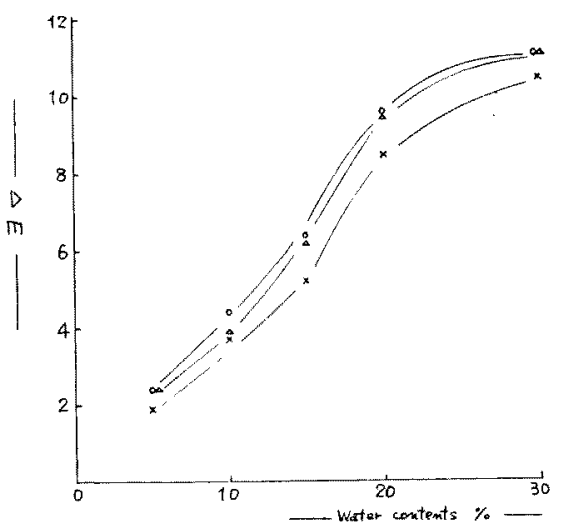

Fig. 1. Relationship between water content and discoloration of "Sakura-dembu" colored with Red 104 by irradiation with ultraviolet ray.

Film: Low density polyethylene

$$
\begin{array}{ll} 
& -O- \\
\text { Polycello } & -\triangle- \\
\text { UV-polypropylene } & -\times-
\end{array}
$$

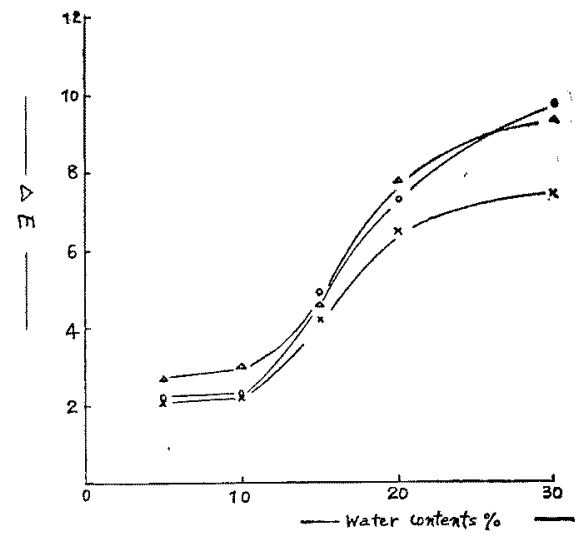

Fig. 2. Relationship between water content and discoloration of "Sakura-dembu" colored with Red 103 by irradiation with ultraviolet ray.

Film: Low density polyethylene

$$
\begin{array}{ll} 
& -\mathrm{O}- \\
\text { Polycello } & -\triangle- \\
\text { UV-polypropylene } & -\mathrm{X}-
\end{array}
$$

し，测色の結果得られた色差 $U E$ 党水分含量と対比せしめて図示すれば，Fig. 1 および Fig. 2 である。 両図に双るごとく，水分の增大と共に色差の增加が認められるが，上昇曲線は 10 20\% の唒で急激に上 昇し，赤色103号においてはとくにこの傾向がいちじるしい。

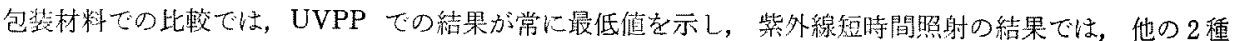
類は近似した弱い保護好果しか示さないことが粗明した。

前述の通り，市販着色でんふ心製品中のそぼろの推定水分量は $15 \sim 20 \%$ をこえる場合が多いので，光線に よる変色を防止するためには，加工法によつて，上り低水分含量とするような効策を考慮すると共に， UVPPの上らな光線の影響を阻止するフィルムの便用についても，一考の余地があるものと考えられる。

\section{要 約}

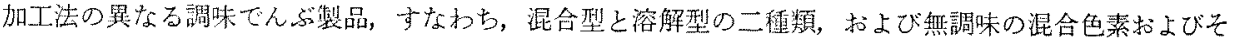

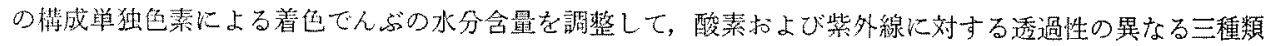
の迊装林料で含気包装し，紫外線照射を苻つた場合の变色を，色差計で測定した結果，次のことが判明した。

1.着色した調味でんぶ製品は，紫外線照射に上つて変色する。

2. 混合色素の中，赤巴 103 号，104 号での着色でん染の及が大きな変色を示し，水分含量の增加に れてその色差杜增大寸る。

3. 水分含量一色差の曲線は直線的ではなく，水分 10〜20\%の間で急激な上䒜が認められる。

4. 包装材料に関しては，常にUVPP 包装によるもの湾色の最低值を示し，含有する紫外線阻止剤の 效果が明らかであつた。

この奏験に当り，fade-meter の使用について便宜をはかられた(株)三越 商品試驗室副部長 加茂定吉氏 に厚く刻繁を表する。

\section{文 献}

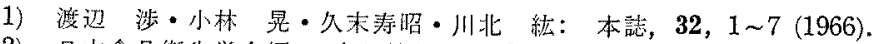

2) 日本食品粥生学全編：食品梭查法, $462 \mathrm{pp}$., 金原出版 (1965).

3) O. KVAALE and E. DALHOFF: Food Technol., 17, 151 153 (1963). 